\title{
Patient characteristics but not virulence factors discriminate between asymptomatic and symptomatic $E$. coli bacteriuria in the hospital
}

Jonas Marschall ${ }^{1,3 *}$, Marilyn L Piccirillo', Betsy Foxman², Lixin Zhang², David K Warren', Jeffrey P Henderson ${ }^{1}$, For the CDC Prevention Epicenters Program

\begin{abstract}
Background: Escherichia coli is a common cause of asymptomatic and symptomatic bacteriuria in hospitalized patients. Asymptomatic bacteriuria (ASB) is frequently treated with antibiotics without a clear indication. Our goal was to determine patient and pathogen factors suggestive of ASB.

Methods: We conducted a 12-month prospective cohort study of adult inpatients with $E$. coli bacteriuria seen at a tertiary care hospital in St. Louis, Missouri, USA. Urine cultures were taken at the discretion of treating physicians. Bacterial isolates were tested for 14 putative virulence genes using high-throughput dot-blot hybridization.

Results: The median age of the 287 study patients was 65 (19-101) years; 78\% were female. Seventy percent had community-acquired bacteriuria. One-hundred ten (38.3\%) patients had ASB and 177 (61.7\%) had symptomatic urinary tract infection (sUTI). Asymptomatic patients were more likely than symptomatic patients to have congestive heart failure $(p=0.03)$, a history of myocardial infarction $(p=0.01)$, chronic pulmonary disease $(p=0.045)$, peripheral vascular disease $(p=0.04)$, and dementia $(p=0.03)$. Patients with sUTI were more likely to be neutropenic at the time of bacteriuria $(p=0.046)$. Chronic pulmonary disease [OR $2.1(95 \% \mathrm{Cl} 1.04,4.1)]$ and dementia [OR 2.4 (95\% Cl 1.02, 5.8)] were independent predictors for asymptomatic bacteriuria. Absence of pyuria was not predictive of ASB. None of the individual virulence genes tested were associated with ASB nor was the total number of genes. Conclusions: Asymptomatic E. coli bacteriuria in hospitalized patients was frequent and more common in patients with dementia and chronic pulmonary disease. Bacterial virulence factors could not discriminate symptomatic from asymptomatic bacteriurias. Asymptomatic E. coli bacteriuria cannot be predicted by virulence screening.
\end{abstract}

Keywords: Escherichia coli, Bacteriuria, Urinary tract infection, Asymptomatic, Virulence factors

\section{Background}

Escherichia coli is the most frequent pathogen to cause symptomatic urinary tract infection (sUTI) but can also lead to asymptomatic bacteriuria. Asymptomatic bacteriuria (ASB) denotes bacterial colonization of the urogenital tract without subjective or systemic host responses. ASB screening and treatment are recommended only during pregnancy [1] and in the preoperative evaluation of men before urological procedures [2], circumstances

\footnotetext{
* Correspondence: jmarscha@dom.wustl.edu

'Division of Infectious Diseases, Washington University School of Medicine, 660 S. Euclid, St. Louis 63110, MO, USA

${ }^{3}$ Department of Infectious Diseases, Bern University Hospital and University of Bern, Friedbühlstr. 51, 3010 Bern, Switzerland

Full list of author information is available at the end of the article
}

where preemptive antibiotic administration decreases the risk of infectious complications [3]. Despite these recommendations, overuse of antibiotics for ASB is common and clearance of bacteriuria is often transient, leading to further treatment courses [4]. Inappropriate antibiotics result in increased healthcare costs and foster antimicrobial resistance [5]; they can even eliminate the protective effect that ASB may have against recurrent UTIs [6]. These issues have led to calls for assessing hospitals' performance in reducing inappropriate antibiotic use nationwide [7].

Surprisingly few studies have compared patients with symptomatic bacteriuria to patients with ASB to identify patient-level risk factors for symptomatic presentation 
or differences in bacterial virulence factors [8-12]. Results from these studies have been inconsistent, reporting either a variety of virulence factors associated with symptomatic bacteriuria [8-11] or no association [12]. We found no previous studies addressing clinical risk factors. Urine cytokines such as interleukin 6 and 8 may be lower in ASB in certain populations [13,14], but an objective test to discriminate ASB from symptomatic bacteriuria is not commercially available. A better understanding of what differentiates ASB from symptomatic bacteriuria could be particularly helpful in patients who are unable to report symptoms, such as intubated patients or those with altered mental status. Here, we used a prospective cohort of patients with $E$. coli bacteriuria as identified by clinicians in a hospital setting. The purpose of our study was to characterize host and pathogen factors associated with $E$. coli ASB that could subsequently be used in predictive models, lead to the development of bedside tests to distinguish ASB from sUTI, or guide treatment decision-making.

\section{Methods}

\section{Study design, data collection, and definitions}

We performed a prospective cohort study of patients with E. coli bacteriuria from August 1st 2009 until July 31st, 2010, at Barnes-Jewish Hospital (BJH), a 1250-bed teaching hospital in eastern Missouri. All adult patients admitted to $\mathrm{BJH}$ who presented with E. coli bacteriuria at time of admission or developed it subsequently were considered for enrollment. Urine cultures were taken at the discretion of the treating physician. The cut-off for significant bacteriuria employed in our hospital microbiology laboratory was $5 \times 10^{4}$ colony-forming units $/ \mathrm{ml}$ in non-catheterized and $5 \times 10^{3}$ in catheterized patients. The bacteriuria was classified as community-acquired if the first positive urine culture occurred within 48 hours of admission. Patients transferred from outside hospitals or long-term care facilities were not considered to have community-acquired bacteriuria. Polymicrobial UTIs were excluded, as were patients who had concurrent bloodstream infection with an organism other than E. coli. We reviewed medical records of those who met inclusion criteria for demographics, medical and urogenital history, and computed Charlson comorbidity and McCabe severity of illness scores. The patients' clinical, laboratory, radiological, and pharmacy data were prospectively reviewed during the admission, including information on all urine and blood cultures. Medication information was entered as start and stop dates and times for each antibiotic with Gram-negative activity.

We classified E. coli bacteriurias based on the patients' urinary symptoms with the objective of determining distinctive features of asymptomatic bacteriuria (ASB). ASB was defined as absence of urinary symptoms. Symptomatic urinary tract infection (sUTI) included cystitis, defined as presence of dysuria, frequency, urinary retention, or lower abdominal pain (without signs of pyelonephritis); or pyelonephritis, defined as the presence of flank pain or tenderness and/or fever. We defined unclassifiable bacteriuria as bacteriuria in a patient who did not fit any of the above criteria or could not report symptoms (e.g., intubation, altered mental status); these patients were excluded from the analysis. If a urinary catheter had been in place in the 48 hours preceding the positive urine culture the bacteriuria was considered as catheter-associated. Past urogenital surgery included all surgeries that resulted in anatomical alteration (e.g. nephrectomy, neobladder formation, prostatic resection, and hysterectomy).

Outcomes of interest were sepsis, sepsis-induced hypotension, E. coli bacteremia, transfer to the ICU within 72 hours of the bacteriuria, length of hospital stay after detection of bacteriuria, and in-hospital mortality. Sepsis and sepsis-induced hypotension were defined using established criteria [15]. Blood cultures were drawn at the discretion of the treating physician and had to occur within \pm 1 day of the bacteriuria. Adequacy of antibiotic therapy was defined as pathogen-directed treatment with antibiotics matching susceptibilities.

\section{Laboratory analyses}

We identified the E. coli isolates from urine cultures of eligible patients in the hospital microbiology laboratory and stored them at $-80^{\circ} \mathrm{C}$ in skim milk. Isolates were processed at the Center for Molecular and Clinical Epidemiology at the School of Public Health, University of Michigan, Ann Arbor, MI. Bacterial DNA was extracted using QIAamp DNA mini kit (QIAGEN, Valencia, CA). DNA probes for the following virulence genes were designed: Hemolysin $(h l y A), \mathrm{P}$ family of fimbriae (prf) [this primer detects all pap adhesions], Dr family of adhesins $(D r), S$ fimbriae $(s f a S)$, cytotoxic necrotizing factor ( $c n f 1)$, aerobactin iron uptake system (iutA), salmochelin iron uptake system (iroN), yersiniabactin iron uptake system $(f y u A)$, group II capsule gene (kpsMT), irgA homologue adhesin (iha), uropathogenic specific protein ( $u s p)$, outer membrane protein $(o m p T)$, the secreted autotransporter toxin (sat), and for chuA (outer heme receptor). The presence of these virulence genes was determined by dot-blot hybridization with fluorescent-labeled probes and a fluorescein-based detection system as described elsewhere [16]. To screen large numbers of isolates in short time periods, we used a microarray system for high-throughput dot-blot hybridization [17]. The frequency of specific virulence genes was compared between symptomatic and asymptomatic patients. Furthermore, bacterial isolates were compared regarding antimicrobial susceptibility patterns. 


\section{Sample size calculations and statistical analysis}

We based our sample size calculations on two studies that reported $34-44 \%$ of bacteriuric patients had symptoms and that males were slightly more likely to have sUTI $[8,18]$. Assuming that male patients account for $65 \%$ in the sUTI and for $45 \%$ in the ASB group and given a 0.05 significance level and $80 \%$ power, we estimated that we would require 88 vs. 132 patients in the two groups, respectively (EpiInfo 3.3.2; accessed at www. cdc.gov/epiinfo/).

Data analysis was performed using SPSS 18 (SPSS Inc., Chicago, IL). Univariate comparisons among categorical variables were performed using the $x^{2}$ test or Fisher's exact test as appropriate. Comparisons among continuous independent variables were performed using Student's t test or Mann Whitney U test as appropriate. A two-sided $p$ value of $<0.05$ was considered significant. Variables found to have a $p \leq 0.1$ on univariate testing were simultaneously entered into a multivariate logistic regression model. The model was tested with goodnessof-fit measures.

The study was approved both by the Washington University Human Research Protection Office and the University of Michigan Institutional Review Board. We obtained a waiver of informed consent from both Boards.

\section{Results}

We identified 337 patients with E. coli bacteriuria during the study period. Of these, 50 (14.8\%) were excluded because they were considered unclassifiable (e.g., intubated patients or patients with acutely altered mental status who were unable to report symptoms). Among the remaining 287 patients, 110 (38.3\%) were classified as having asymptomatic bacteriuria, and 177 (61.7\%) as having symptomatic UTI. Two hundred and twenty-five patients were female (78.4\%), and 169 (58.9\%) were white (Table 1). Age had a bimodal distribution, with a small peak between 20 and 25 years and a larger peak between 60 to 80 years; the median age was 65 years (range, 19-101). Among symptomatic patients, 70 (39.4\%) had cystitis, and 107 (61.6\%) pyelonephritis. In this group of symptomatic patients, 91 (51.4\%) were tested for bloodstream infection, and 20 had positive blood cultures. Among asymptomatic patients, 35 (31.8\%) had blood cultures taken, and one was positive for E. coli.

\section{Comparison of patient risk factors for asymptomatic bacteriuria}

Asymptomatic patients were more likely than symptomatic patients to have congestive heart failure $(p=0.03)$, a history of myocardial infarction $(\mathrm{p}=0.01)$, chronic pulmonary disease $(p=0.045)$, peripheral vascular disease $(\mathrm{p}=0.04)$, and dementia $(\mathrm{p}=0.03)$ (Table 1$)$. Conversely, patients with symptomatic UTI were more likely to be neutropenic at the time of bacteriuria $(p=0.046)$. Subsets of catheter-associated bacteriuria were similar in the two groups $(\mathrm{p}=0.5)$. Also, there was no difference in the subset of complicated bacteriurias between the groups [95 (86\%) among asymptomatic vs. 153 (86\%); p = 1.0].

\section{Comparison of virulence factors for asymptomatic bacteriuria}

We also compared the prevalence of virulence genes in the bacterial isolates from both groups (see Table 2). The most frequently detected virulence factors were chuA (83.3\%), fyuA (82.9\%), and ompT (79.8\%). There were no statistically significant differences encountered. The total number of virulence factors per isolate did not differ between asymptomatic [median 6.5 (range, 0-13)] and symptomatic [median $7(0-12)$ ] patients $(\mathrm{p}=0.2)$.

When comparing the resistance pattern of bacterial isolates there was no difference in resistance to the most frequently used antibiotics ciprofloxacin [41/110 (37\%) among sUTI vs. 57/177 (32\%) among ASB patients; $\mathrm{p}=0.4]$ or trimethoprim/sulfamethoxazole [32/110 (29\%) vs. $45 / 177$ (25\%); $\mathrm{p}=0.5]$.

\section{Multivariate analysis of risk factors for asymptomatic bacteriuria}

We performed a multivariate analysis of risk factors for ASB entering variables that had a $p \leq 0.1$ in univariate analysis. Based on the numbers of ASB cases we intended to include a maximum of 10-12 variables into the model. Neutropenia, congestive heart failure, chronic pulmonary disease, history of myocardial infarction, peripheral vascular disease, dementia, and pyuria were entered into the model. Chronic pulmonary disease [OR 2.1 (95\% CI 1.04, 4.1)] and dementia [OR 2.4 (95\% CI $1.02,5.8)$ ] were independent predictors for asymptomatic bacteriuria. Pyuria was not associated with symptomatic UTI. The Hosmer-Lemeshow test indicated a good fit for the data $(\mathrm{p}=0.3)$.

\section{Clinical outcomes}

There was no difference in the proportion of patients requiring admission to the intensive care unit between the two groups $[11$ (10\%) ASB vs. 22 (12\%) sUTI; $\mathrm{p}=0.5]$. Symptomatic UTI patients were more likely to meet sepsis criteria [108 (61\%) vs. 38 (35\%); p < 0.001] and develop sepsis-induced hypotension [41 (23\%) vs. 7 (6\%); $\mathrm{p}<0.001]$. Twelve patients died during their hospital admission (4.2\%). There was no difference in mortality $(\mathrm{p}=0.5)$ nor in length of hospital stay after the bacteriuria whether it was symptomatic or not $(\mathrm{p}=0.2)$.

Fewer ASB patients received pathogen-directed antibiotic treatment during the hospitalization [89 (81\%) vs. 168 (95\%); $\mathrm{p}<0.001]$. Among those receiving antibiotic 
Table 1 Comparison of 110 patients with asymptomatic bacteriuria to 177 patients with symptomatic urinary tract infection due to $E$. coli

\begin{tabular}{|c|c|c|c|c|}
\hline Variable & $\begin{array}{c}\text { Asymptomatic } \\
\text { bacteriuria }(n=110)\end{array}$ & $\begin{array}{l}\text { Symptomatic urinary tract } \\
\text { infection }(n=177)\end{array}$ & $\mathrm{p}$ value & $\begin{array}{c}\text { Adjusted odds ratio } \\
(95 \% \mathrm{Cl})^{*} \\
\end{array}$ \\
\hline & n (\%) & n (\%) & & \\
\hline Gender (male) & $19(17)$ & $43(24)$ & 0.2 & \\
\hline Age (years, median, range) & $67(20,100)$ & $64(19,101)$ & 0.1 & \\
\hline Race (white) & $68(62)$ & $101(57)$ & 0.4 & \\
\hline Body mass index $\left(\mathrm{kg} / \mathrm{m}^{2}\right.$, mean, $\left.\pm \mathrm{SD}\right)$ & $28.9( \pm 8.4)$ & $28.9( \pm 9.9)$ & 1.0 & \\
\hline Diabetes mellitus & $39(36)$ & $53(30)$ & 0.3 & \\
\hline Renal insufficiency $(\mathrm{Cr}>1.5 \mathrm{mg} / \mathrm{dl})$ & $23(21)$ & $37(21)$ & 1.0 & \\
\hline Any malignancy & $28(26)$ & $44(25)$ & 0.9 & \\
\hline Any transplant & $3(3)$ & $9(5)$ & 0.3 & \\
\hline Neutropenia at time of bacteriuria (ANC <1000/ul) & 0 & $7(4)$ & 0.046 & \\
\hline Pregnancy & $5(5)$ & $8(6)$ & 1.0 & \\
\hline Congestive heart failure & $26(24)$ & $24(14)$ & 0.03 & \\
\hline Myocardial infarction & $23(21)$ & $18(10)$ & 0.01 & \\
\hline Chronic pulmonary disease & $25(23)$ & $24(14)$ & 0.045 & $2.1(1.04-4.1)$ \\
\hline Peripheral vascular disease & $9(8)$ & $5(3)$ & 0.04 & \\
\hline Oral steroid medication & $6(5)$ & $15(8)$ & 0.3 & \\
\hline Dementia & $15(14)$ & $11(6)$ & 0.03 & $2.4(1.02-5.8)$ \\
\hline History of cerebrovascular accident & $24(22)$ & $36(20)$ & 0.8 & \\
\hline Hemi- or paraplegia & $13(12)$ & $14(8)$ & 0.3 & \\
\hline Functional or anatomical urinary tract abnormalities & $31(28)$ & $54(31)$ & 0.7 & \\
\hline Voiding dysfunction & $26(24 \%)$ & $54(31 \%)$ & 0.2 & \\
\hline Benign prostatic hyperplasia $(n=62)$ & $3 / 19(16)$ & $15 / 43(35)$ & 0.1 & \\
\hline History of urogenital surgery & $30(27)$ & $61(34)$ & 0.8 & \\
\hline Urological procedure this admission & 0 & $5(3)$ & 0.2 & \\
\hline Charlson comorbidity index (mean, \pm SD) & $3.1( \pm 2.6)$ & $2.8( \pm 2.8)$ & 0.2 & \\
\hline McCabe severity-of-illness score (median, range) & $1(1,2)$ & $1(1,3)$ & 0.2 & \\
\hline Cystitis & - & $70(39)$ & - & \\
\hline Pyelonephritis & - & $107(62)$ & - & \\
\hline Sepsis & $38(35)$ & $108(61)$ & $<0.001$ & \\
\hline Sepsis-induced hypotension & $7(6)$ & $41(23)$ & $<0.001$ & \\
\hline Community-acquired bacteriuria & $75(68)$ & $127(72)$ & 0.5 & \\
\hline Urinary catheter-associated bacteriuria & $22(20)$ & $30(17)$ & 0.5 & \\
\hline Urinalysis with pyuria (>10 WBC/hpf) & $65(63)$ & $121(74)$ & 0.1 & \\
\hline Isolate resistant to ciprofloxacin & $57(32 \%)$ & $41(37 \%)$ & 0.4 & \\
\hline Isolate resistant to trimethoprim/ sulfamethoxazole & $45(25 \%)$ & $32(29 \%)$ & 0.5 & \\
\hline \multicolumn{5}{|l|}{ Outcomes } \\
\hline Pathogen-directed antibiotic treatment & $89(81)$ & $168(95)$ & $<0.001$ & \\
\hline Length of hospital stay (mean, \pm SD) & $5.5( \pm 7.7)$ & $6.6( \pm 7.5)$ & 0.2 & \\
\hline In-hospital mortality & $4(3.6)$ & $8(5)$ & 0.5 & \\
\hline
\end{tabular}

NOTE. $C l=$ confidence interval. $S D=$ standard deviation. $C r=$ creatinine. $A N C=$ absolute neutrophil count. $W B C=$ white blood cells. $H P F=$ high-power field. * The variables included in the final model were neutropenia, congestive heart failure, chronic pulmonary disease, history of myocardial infarction, peripheral vascular disease, dementia, and pyuria. 
Table 2 Comparison of virulence genes present in E. coli isolates from 287 patients with asymptomatic bacteriuria or symptomatic urinary tract infection

\begin{tabular}{lccc}
\hline Variable & $\begin{array}{c}\text { Asymptomatic } \\
\text { bacteriuria } \\
(\mathbf{n}=\mathbf{1 1 0})\end{array}$ & $\begin{array}{c}\text { Symptomatic } \\
\text { urinary tract } \\
\text { infection }(\mathbf{n}=\mathbf{1 7 7})\end{array}$ & p value \\
\hline chuA & $\mathrm{n}(\%)$ & \\
fyuA & $90(81.8)$ & $149(84.2)$ & 0.6 \\
ompT & $91(82.7)$ & $147(83.1)$ & 0.9 \\
usp & $83(75.5)$ & $146(82.5)$ & 0.15 \\
kpsMT (group II capsule) & $59(53.6)$ & $95(53.7)$ & 1.0 \\
iucD & $49(44.5)$ & $89(50.3)$ & 0.3 \\
iha & $51(46.4)$ & $70(39.5)$ & 0.3 \\
sat & $43(39.1)$ & $75(42.4)$ & 0.6 \\
prf (P family of fimbriae) & $28(25.5)$ & $51(28.8)$ & 0.5 \\
iroN & $25(22.7)$ & $40(22.6)$ & 1.0 \\
hlyA & $19(17.3)$ & $38(21.5)$ & 0.4 \\
sfa & $20(18.2)$ & $30(16.9)$ & 0.8 \\
cnf1 & $13(11.8)$ & $20(11.3)$ & 0.9 \\
Dr & $6(5.5)$ & $14(7.9)$ & 0.4 \\
\hline
\end{tabular}

treatment, the mean time from detection of bacteriuria to receipt of appropriate antibiotics was shorter for symptomatic patients $[15.9$ hours $( \pm 26.8)$ vs. 22.4 hours $( \pm 23.2) ; \mathrm{p}=0.07)$. We did, however, not compare treatment variation in the antibiotic therapy as part of this analysis and antibiotic prescriptions at hospital discharge were not taken into account.

\section{Discussion}

Why E. coli bacteriuria is associated with urinary tract symptoms in some instances but not in others remains incompletely understood. This knowledge gap may explain why $E$. coli bacteriuria is often treated with antibiotics independent of any symptoms [19]. Overtreatment in turn generates added cost and can facilitate the development of antibiotic resistance. It would therefore be invaluable if we had tools to differentiate between symptomatic infection and asymptomatic bacteriuria (and to understand which bacteriurias result in morbidity in patients who are unable to report symptoms). Here, we report a comparison of patient characteristics and virulence factors between symptomatic and asymptomatic patients with $E$. coli bacteriuria. While we found independent clinical predictors for asymptomatic bacteriuria (chronic pulmonary disease, dementia) no virulence pattern could be associated with the corresponding E. coli isolates.

To our knowledge there are no published studies of patient characteristics to differentiate ASB from symptomatic UTI. We found the comorbidities chronic pulmonary disease and dementia to be associated with asymptomatic bacteriuria. It is conceivable that underlying dementia resulted either in poor symptom recognition by the affected patients or may have impaired their ability to report symptoms. ASB is also much more prevalent in elderly long-term care residents [20] who are prone to cognitive deficits, and cognitive changes may be a risk factor for ASB [21]. Other potential contributors are poor perineal hygiene and incomplete bladder emptying. It is less clear why chronic pulmonary disease should be associated with ASB; this may be due to different screening practices in medical subspecialties or a spurious finding. Those with ASB may finally represent a group of patients in which it was more difficult to find a diagnosis and urine cultures were part of the broad work-up.

A small number of studies have determined differences in bacterial virulence factors between strains causing ASB and sUTI. Mabbett et al. compared 57 ASB strains to 45 cystitis/pyelonephritis strains not only in regard to their virulence genes but also in gene product expression and epithelial adhesion studies [8]. PapGII (47\% vs. 16\%) and $a f a(29 \%$ vs. $11 \%)$ were associated with sUTI as were hemolysin expression, siderophore expression, and adhesion to epithelial cells. However, the authors noted that ASB and sUTI strains tended to be phylogenetically related. The latter finding was confirmed by Takahashi et al. who investigated virulence factors in $283 \mathrm{E}$. coli urinary isolates from a hospital in Japan, and also saw a similar distribution of serotypes across ASB and sUTI isolates. The virulence genes iha (31\% vs. $13 \%)$, ompT ( $82 \%$ vs. $70 \%$ ) and $P A I$, which refers to the so-called genomic "pathogenicity island" (65\% vs. 50\%), were all significantly more frequent in strains causing sUTI [9]. Although ompT was a common virulence gene in our similar-sized cohort, the sUTI strains we analyzed did not carry omp $T$ more frequently (83\% vs. $76 \%)$. A number of smaller studies in subpopulations like pregnant women and patients with spinal cord injuries found other virulence factors to be associated with symptomatic infections $[10,11]$ or were negative [22]. In addition to the bacterial characteristics mentioned above, there have been reports that ASB strains can be identified based upon their capability to form biofilms in vitro [23], for which we did not screen our isolates. With 287 patient samples our cohort is one of the largest to date; however, we did not find any virulence gene to predominate in the subset of symptomatic patients. One of the possible explanations for this negative finding is that virulence genes in ASB may carry deletions that block gene expression [24-26]; therefore, ASB strains may look more virulent by genotype than they actually are in vivo. Another possibility is that virulence factors other than those we examined are more relevant in determining pathogenicity [27]. Yet another possibility is that the 
major determinant of symptom development is unrelated to pathogen factors, but due to unmeasured factors such as the host's innate immune response [28-30]. Future research should incorporate studies of the host's defense mechanisms (e.g., toll-like receptor polymorphisms) into a multi-faceted analysis of symptom development in bacteriuria.

There are a number of limitations to our study. Including only patients that were tested for and found to have bacteriuria may have introduced selection bias. We suspect that this bias was particularly relevant for ASB patients which were included despite an indication for culturing. Symptoms at the time of bacteriuria were taken from hospital charts entered by physicians and nurses; therefore patient symptoms may have been underreported. We did not obtain urine samples to determine whether virulence factors were expressed in vivo, nor test gene expression of the bacterial isolates in vitro. Also, we elected to test for a specific set of virulence factors but may have missed others that are not identified yet. Blood cultures were ordered by the treating physicians and may have missed septic or febrile patients at risk for bacteremia. Lastly, we did this study at a single tertiary-care center and the findings may not be generalizable to other settings. This also goes for the high levels of resistance to the most commonly used antimicrobials that we encountered here.

\section{Conclusions}

In summary, our study is the largest cohort study to analyze both patient and pathogen factors associated with asymptomatic versus symptomatic bacteriuria, was conducted prospectively and included both genders. Novel predictive factors (chronic pulmonary disease, dementia) were identified that could serve for clinical decisionmaking on antibiotic treatment. Host susceptibility (i.e., characteristics of an individual's innate immune system) may be more relevant for symptom development in $E$. coli bacteriuria than virulence determinants.

\section{Competing interest}

None of the following authors has a conflict of interest (J Marschall: no conflict, ML Piccirillo: no conflict, JP Henderson: no conflict). DK Warren is a Consultant for $3 \mathrm{M}$ Healthcare and Cardinal Health, Inc., and receives research funding from Sage Products, Inc., 3 M Healthcare, BioMérieux, and Cubist Pharmaceuticals.

\section{Authors' contributions}

JM conceived and designed the study, did the statistical analyses, and drafted the manuscript. MLP abstracted the clinical data and helped draft the manuscript. BF and LZ oversaw the laboratory analyses and reviewed the manuscript. DKW and JPH helped design the study and reviewed the manuscript. All authors read and approved the final version of the manuscript.

\section{Acknowledgements}

JM received support from the NIH CTSA (UL1RR024992) in form of a KL2 Career Development Grant (KL2RR024994), and is currently the recipient of a Building Interdisciplinary Research Careers in Women's Health (BIRCWH) award through the NIH NCATS, a career development award (5K12HD001459-13). He is also the section leader for a subproject of the CDC Prevention Epicenters Program grant (U54 CK000162; PI Fraser). In addition, JM is funded by the Barnes-Jewish Hospital Patient Safety \& Quality Fellowship Program and a Washington University Institute of Clinical and Translational Sciences (ICTS) research grant.

LZ is supported in part by a UM MICHR CTSA grant (UL1RR024986). BF is supported in part by an interdisciplinary training program grant at the University of Michigan (5T32Al049816-10), by NICHD (5R01HD038098-07) and NIDDK (5R21DK085290-02). JPH holds a career award for medical scientists from the Burroughs-Wellcome Fund and receives additional support from NIH HD000459-09 and HL101263-01. DKW is supported in part by a CDC Prevention Epicenter Program grant (CDC 1U1CI000033301).

We thank Kyle Ota who assisted with the collection of patient data, and Cherie Hill and Dorothy Sinclair for their invaluable help with data management. The study would also not have been possible without Joan Hoppe-Bauer and Linda Chase who were instrumental in setting up the isolate identification and storage system. In Ann Arbor, Sreelatha Ponnaluri organized the isolate storage, and Mikiko Senga helped with DNA extraction in preparation for the microarray analyses.

\section{Author details}

${ }^{1}$ Division of Infectious Diseases, Washington University School of Medicine, 660 S. Euclid, St. Louis 63110, MO, USA. ${ }^{2}$ School of Public Health, University of Michigan, Ann Arbor, MI, USA. ${ }^{3}$ Department of Infectious Diseases, Bern University Hospital and University of Bern, Friedbühlstr. 51, 3010 Bern, Switzerland.

Received: 9 January 2013 Accepted: 2 May 2013

Published: 10 May 2013

\section{References}

1. Lin K, Fajardo K: Screening for asymptomatic bacteriuria in adults: evidence for the U.S. Preventive Services Task Force reaffirmation recommendation statement. Ann Intern Med 2008, 149(1):20-24.

2. Nicolle LE: Asymptomatic bacteriuria: review and discussion of the IDSA guidelines. Int J Antimicrob Agents 2006, 28(Suppl 1):S42-S48.

3. Nicolle LE, Bradley S, Colgan R, Rice JC, Schaeffer A, Hooton TM: Infectious Diseases Society of America guidelines for the diagnosis and treatment of asymptomatic bacteriuria in adults. Clin Infect Dis 2005, 40(5):643-654.

4. Dalal S, Nicolle L, Marrs CF, Zhang L, Harding G, Foxman B: Long-term Escherichia coli asymptomatic bacteriuria among women with diabetes mellitus. Clin Infect Dis 2009, 49(4):491-497.

5. Gupta K, Scholes D, Stamm WE: Increasing prevalence of antimicrobial resistance among uropathogens causing acute uncomplicated cystitis in women. JAMA 1999, 281(8):736-738.

6. Cai T, Mazzoli S, Mondaini N, Meacci F, Nesi G, D'Elia C, Malossini G, Boddi V, Bartoletti R: The role of asymptomatic bacteriuria in young women with recurrent urinary tract infections: to treat or not to treat? Clin Infect Dis 2012, 55(6):771-777.

7. Gross PA, Patel B: Reducing antibiotic overuse: a call for a national performance measure for not treating asymptomatic bacteriuria. Clin Infect Dis 2007, 45(10):1335-1337.

8. Mabbett AN, Ulett GC, Watts RE, Tree JJ, Totsika M, Ong CL, Wood JM, Monaghan W, Looke DF, Nimmo GR, et al: Virulence properties of asymptomatic bacteriuria Escherichia coli. Int J Med Microbiol 2009, 299(1):53-63.

9. Takahashi A, Kanamaru S, Kurazono H, Kunishima Y, Tsukamoto T, Ogawa O, Yamamoto S: Escherichia coli isolates associated with uncomplicated and complicated cystitis and asymptomatic bacteriuria possess similar phylogenies, virulence genes, and O-serogroup profiles. J Clin Microbiol 2006, 44(12):4589-4592.

10. Hull RA, Rudy DC, Wieser IE, Donovan WH: Virulence factors of Escherichia coli isolates from patients with symptomatic and asymptomatic bacteriuria and neuropathic bladders due to spinal cord and brain injuries. J Clin Microbiol 1998, 36(1):115-117.

11. Graham JC, Leathart JB, Keegan SJ, Pearson J, Bint A, Gally DL: Analysis of Escherichia coli strains causing bacteriuria during pregnancy: selection for strains that do not express type 1 fimbriae. Infect Immun 2001, 69(2):794-799. 
12. Hooton TM, Scholes D, Stapleton AE, Roberts PL, Winter C, Gupta K, Samadpour M, Stamm WE: A prospective study of asymptomatic bacteriuria in sexually active young women. N Engl J Med 2000, 343(14):992-997.

13. Benson M, Jodal U, Agace W, Hellstrom M, Marild S, Rosberg S, Sjostrom M, Wettergren B, Jonsson S, Svanborg C: Interleukin (IL)-6 and IL-8 in children with febrile urinary tract infection and asymptomatic bacteriuria. $J$ Infect Dis 1996, 174(5):1080-1084.

14. Rodhe N, Lofgren S, Strindhall J, Matussek A, Molstad S: Cytokines in urine in elderly subjects with acute cystitis and asymptomatic bacteriuria. Scand J Prim Health Care 2009, 27(2):74-79.

15. Bone RC, Balk RA, Cerra FB, Dellinger RP, Fein AM, Knaus WA, Schein RM, Sibbald WJ, The ACCP/SCCM Consensus Conference Committee. American College of Chest Physicians/Society of Critical Care Medicine: Definitions for sepsis and organ failure and guidelines for the use of innovative therapies in sepsis. Chest 1992, 101(6):1644-1655.

16. Bauer RJ, Zhang L, Foxman B, Siitonen A, Jantunen ME, Saxen H, Marrs CF: Molecular epidemiology of 3 putative virulence genes for Escherichia coli urinary tract infection-usp, iha, and iroN(E. coli). J Infect Dis 2002, 185(10)):1521-1524.

17. Zhang L, Srinivasan U, Marrs CF, Ghosh D, Gilsdorf JR, Foxman B: Library on a slide for bacterial comparative genomics. BMC Microbiol 2004, 4:12.

18. Silver SA, Baillie L, Simor AE: Positive urine cultures: A major cause of inappropriate antimicrobial use in hospitals? Can J Infect Dis Med Microbiol 2009, 20(4):107-111

19. Gandhi T, Flanders SA, Markovitz E, Saint S, Kaul DR: Importance of urinary tract infection to antibiotic use among hospitalized patients. Infect Control Hosp Epidemiol 2009, 30(2):193-195.

20. Colgan R, Nicolle LE, McGlone A, Hooton TM: Asymptomatic bacteriuria in adults. Am Fam Physician 2006, 74(6):985-990

21. Ariathianto Y: Asymptomatic bacteriuria - prevalence in the elderly population. Aust Fam Physician 2011, 40(10):805-809.

22. Lavigne JP, Boutet-Dubois A, Laouini D, Combescure C, Bouziges N, Mares $P$, Sotto A: Virulence potential of Escherichia coli strains causing asymptomatic bacteriuria during pregnancy. J Clin Microbiol 2011, 49(11):3950-3953.

23. Hancock V, Ferrieres L, Klemm P: Biofilm formation by asymptomatic and virulent urinary tract infectious Escherichia coli strains. FEMS Microbiol Lett 2007, 267(1):30-37.

24. Roos V, Ulett GC, Schembri MA, Klemm P: The asymptomatic bacteriuria Escherichia coli strain 83972 outcompetes uropathogenic E. coli strains in human urine. Infect Immun 2006, 74(1):615-624.

25. Zdziarski J, Svanborg C, Wullt B, Hacker J, Dobrindt U: Molecular basis of commensalism in the urinary tract: low virulence or virulence attenuation? Infect Immun 2008, 76(2):695-703.

26. Henderson JP, Crowley JR, Pinkner JS, Walker JN, Tsukayama P, Stamm WE, Hooton TM, Hultgren SJ: Quantitative metabolomics reveals an epigenetic blueprint for iron acquisition in uropathogenic Escherichia coli. PLOS Pathog 2009, 5(2):e1000305.

27. Vigil PD, Stapleton AE, Johnson JR, Hooton TM, Hodges AP, He Y, Mobley $\mathrm{HL}$ : Presence of Putative Repeat-in-Toxin Gene tosA in Escherichia coli Predicts Successful Colonization of the Urinary Tract. MBio 2011, 2:3.

28. Svanborg C, Bergsten G, Fischer H, Godaly G, Gustafsson M, Karpman D, Lundstedt AC, Ragnarsdottir B, Svensson M, Wullt B: Uropathogenic Escherichia coli as a model of host-parasite interaction. Curr Opin Microbiol 2006, 9(1):33-39.

29. Hernandez JG, Sunden F, Connolly J, Svanborg C, Wullt B: Genetic control of the variable innate immune response to asymptomatic bacteriuria. PLoS One 2011, 6(11):e28289.

30. Hawn TR, Scholes D, Wang H, Li SS, Stapleton AE, Janer M, Aderem A, Stamm WE, Zhao LP, Hooton TM: Genetic variation of the human urinary tract innate immune response and asymptomatic bacteriuria in women. PLoS One 2009, 4(12):e8300.

doi:10.1186/1471-2334-13-213

Cite this article as: Marschall et al:: Patient characteristics but not virulence factors discriminate between asymptomatic and symptomatic E. coli bacteriuria in the hospital. BMC Infectious Diseases 2013 13:213.

\section{Submit your next manuscript to BioMed Central and take full advantage of:}

- Convenient online submission

- Thorough peer review

- No space constraints or color figure charges

- Immediate publication on acceptance

- Inclusion in PubMed, CAS, Scopus and Google Scholar

- Research which is freely available for redistribution

Submit your manuscript at www.biomedcentral.com/submit
C) BioMed Central 